\title{
Methane Activation Process: Simultaneous Optimization of Methane Conversion and Aromatic Yields using Zn-ZSM-11 Zeolite
}

\author{
Oscar A. Anunziata* and Jorgelina Cussa
}

\author{
Grupo Fisicoquímica de Nuevos Materiales, Centro de Investigación y Tecnología Química (CITeQ), Facultad \\ Córdoba, Universidad Tecnológica Nacional, (5016) - Córdoba-Argentina
}

\begin{abstract}
Experiment Design - Response Surface Methodology (RSM) is used to model and to optimize the activation of Methane (C1) using Ethane (C2) as co-reactant into higher hydrocarbons, over Zn-containing zeolite catalyst. The application of this methodology in this work, allows a better understanding of the influence of the different factors; on two responses simultaneously: C1 Conversion and Aromatic Hydrocarbons Yields. Box-Behnken Design was development and the Responses Surfaces were defined, finding the best combination in the reaction parameters in order to optimize the process. Applying the statistic methodology, the best operation conditions obtained are: high $\mathrm{C} 1$ conversion $(48.6 \mathrm{~mol} \%$ C) and Aromatic Hydrocarbons Yields $(47.2 \mathrm{~mol} \%)$ were achieved working at these conditions, advancing to the results recently reported by us, where only one objective function (C1 conversion) was optimized.
\end{abstract}

Keywords: Experiment Design, Response Surface, Two Responses Optimization, Methane activation, ethane co-reactant.

\section{INTRODUCTION}

The natural gas (NG) constitutes a great energy source, economic and accessible, having an impact in the world energy balance, considered as an alternative source of fuel and other petrochemical products. The activation and the direct conversion of methane are a promising approach for the utilization of natural gas resource and also a great challenge in the science of catalysis. In previous works, the aromatization of $\mathrm{C} 1$ using various light paraffin as co-reactant was reported using Zn-ZSM11 catalyst [1-3]. C1 would be activated under non-oxidizing condition by interaction with $\mathrm{C} 2$ and with LPG. Very high levels of C1 conversion to Aromatic Hydrocarbons were obtained by interaction with $\mathrm{C} 2$ (molar fraction in the feed: $\mathrm{C} 1 / \mathrm{C} 1+\mathrm{C} 2=0.4-0.8$ ) over $\mathrm{Zn}$ ZSM-11 (molar fraction $\mathrm{Zn} / \mathrm{Zn}+\mathrm{H}=0.86$ ) at $550{ }^{\circ} \mathrm{C}$ and total pressure of $1 \mathrm{~atm}$; with the aromatic hydrocarbon yield between 10-40 mol \% C1 [3]. Anunziata et al. [1] reported that, in the activation of $\mathrm{C} 1$ with LPG, Aromatic Hydrocarbons were the main products in the whole range of $\mathrm{C} 1$ molar fractions (0.4-0.85), reaching to higher levels of $\mathrm{C} 1$ conversion (10-45\%). Anunziata et al. reported the optimizations of methane activation with ethane over Zn-H-ZSM-11 zeolite, on one response: $\mathrm{C} 1$ Conversion [4].

The statistical experiments design is the process of planning an experiment to obtain appropriate data that can be analyzed by statistical methods, to produce concrete and valid conclusions. The objective of all experiment includes the descriptions of the responses to the treatment factors. The origin of the experiments design was in the twenties by the mathematician Fisher [5]; also Box [6-8], Cox [9],

*Address correspondence to this autor Grupo Fisicoquímica de Nuevos Materiales, Centro de Investigación y Tecnología Química (CITeQ), Facultad Córdoba, Universidad Tecnológica Nacional, (5016)-CórdobaArgentina; Tel/Fax: 54-351-4690585;

E-mail: oanunziata@scdt.frc.utn.edu.ar
Kempthorne [10] and Cochran [11], have contributed on the design of experiments. Box and Wilson's work [6] and statistical methods, developed for modeling phenomena and to find combinations of a number of experimental factors led to most favorable response. One of the main advantages in the response curve is to visualize the response for all levels of the experimental factors [6]. Specifically, the response surface design is classified as a simultaneous method, being used in the stage of optimization [12]. Their application allows selecting the optimum combination of levels, to obtain the best response for a specific condition [13]. In the RSM, factorial designs are carried out and the results are adjusted using mathematical models. They are known as displacement and design stages, respectively; they are repeated several times, screening the response surface obtained in the direction of the region of the optimum point.

The response surface allows inspecting, in a visual way, the response for certain area of the levels of the factors, allowing us to:

- Determine the combination of the factors levels that provides a good operative condition.

- Find the combination of levels that provides economic improvements.

- Investigate the mutual influence of the factors on the response variables, in analytic studies of fundamental processes.

Specifically, the response surface design is classified as a simultaneous method, being used in the stage of optimization. Their application allows selecting the optimum combination of levels, to obtain the best response for a specific condition [13]. The response $y$ is described by a polynomial function of various independent variables $x i$ [13]:

$y=f(x i)+\varepsilon$ 
where $\varepsilon$ represents the observed error in the response $y$.

The response surface design and the strategic analysis implied that the response variable $(\mu y)$ is in function of the levels of quantitative factors represented by the variables $x 1, x 2, \ldots, x k$.

The polynomial models are used as practical approach to the real response function. The polynomial models commonly used for the analysis response surface are [6]:

- the lineal models of first order, applied to two factors:

$\mu y=\beta 0+\beta 1 x 1+\beta 2 x 2$

- the quadratic model, or of second order, for two factors:

$\mu y=\beta 0+\beta 1 x 1+\beta 2 x 2+\beta 11 x^{2} 1+\beta 22 x^{2} 2+\beta 12 x 1 \times 2$

One approach to optimal performance is to vary one factor while keeping the other factors constant in order to get improved response with respect to the varied factor. This often does not bring about the effect of interaction of various parameters as compared to factorial design [11]. Response surface methodology is a useful model for studying the effect of several factors influencing the response by varying them simultaneously. The experimental design recently has been applied in the optimization of several processes [14-18].

Process modeling and optimization are very important matters in engineering to meet the stringent quality requirements in a globally competitive market [19]. The success of a process depends on the use of artificial intelligent techniques which are able to code operational knowledge and use this information for deciding optimal strategies for operations. In most of processes, more than one response has to be considered for optimization of process parameters. Therefore it is necessary to simultaneously optimize the responses that the researcher desires. In essence, the problem of optimization of various responses involves the selection of set conditions or independent variables that give an ideal result [20]. The hope is to select the levels of independent variables that optimize all the responses at the same time. Experiment design-response surface methodology (RSM) is used in this work to model and to optimize two responses in the process of activation of methane (C1) using ethane (C2) as coreactant into higher hydrocarbons, over $\mathrm{Zn}$-containing zeolite catalyst. The application of this methodology allows a better understanding of the influence of the different factors: time on stream (TOS), space velocity of C2 (GHSV-C2), molar fraction of $\mathrm{C} 1 /(\mathrm{C} 1+\mathrm{C} 2)(\mathrm{XC} 1)$ and reaction temperature, on two responses simultaneously: $\mathrm{C} 1$ conversion and its conversion to Aromatic Hydrocarbons, achieving efficiency and effectiveness of this process. Box-Behnken design was development with different levels of the factors, determining its influence on the $\mathrm{C} 1$ conversion to Aromatic Hydrocarbons in order to obtain responses surfaces.

\section{MATERIALS AND METHODOLOGY}

\subsection{Reaction Conditions}

The catalytic reactions of $\mathrm{C} 1+\mathrm{C} 2$ were carried out in a continuous flow quartz reactor at atmospheric pressure, with an inner diameter of $10 \mathrm{~mm}$ at different reaction temperature over a $\mathrm{Zn}-\mathrm{ZSM}-11$ catalyst $\left(\mathrm{Si} / \mathrm{Al}=17 ; 2.5 \mathrm{wt} \%\right.$ of $\mathrm{Zn}^{2+}$ as counter ion). Products were withdrawn periodically from the outlet of the reactor and analyzed by on-line gas chromatography equipped with a FID detector. The following reactants were used as feed: high purity methane $(>99.97 \%)$ and ethane $(>99.997 \%)$ supplied by AGA. The reaction products were analyzed using a 2 m Porapak Q column [3].

\subsection{Factors}

A Box-Behnken design was applied, the variables studied were: TOS, GHSV of ethane, Molar fraction of $\mathrm{C} 1 / \mathrm{C} 2+\mathrm{C} 1$ and reaction temperature. The natural variables (factors): TOS, GHVS-C2, XC1 and reaction temperature were codified for a better treatment of the data. This is a simple linear transformation of the original measurement scale for a factor; thus, the high value becomes +1 and the low value becomes -1 . The Table 1 shows the factors levels used:

The responses analyses were: $\mathrm{Y}_{1}$ (response): $\mathrm{C} 1$ conversion $(\mathrm{mol} \% \mathrm{C})$ and $\mathrm{Y}_{2}$ (response): Aromatic Hydrocarbons Yields (mol\% C).

\subsection{Experimental Design - Response Surface}

In the response surface methodology (RSM), factorial designs are carried out, and the results are adjusted using mathematical models. These stages are known as displacement stage and design, respectively; these are repeated several times, screening the response surface obtained in the direction of the region of the best optimum point.

A Box-Behnken design was applied in theses study. The complete design is shown in Table $\mathbf{2}$, it was analyzed by statistical soft: Statgraphics and Statistica.

The analysis of variance (ANOVA) [12] partitions the variability of the response into separate pieces, for each of the effects. Then the ANOVA tests the statistical significance of each effect by comparing the mean square against an estimate of the experimental error.

\section{RESULTS}

\subsection{Response: C1 Conversion}

The results obtained by the ANOVA test are shown in Table 3 .

Table 1. Coded and Decoded Levels of the Factors

\begin{tabular}{|c|c|c|c|c|}
\hline Coded Levels & $X_{1}:$ TOS $(\mathbf{m i n})$ & $\boldsymbol{X}_{2}:$ GHSV-C2 $(\mathbf{m l} / \mathbf{g} \mathbf{h})$ & $\boldsymbol{X}_{3}:$ XC1 & $\boldsymbol{X}_{\mathbf{4}}:$ Reaction Temperature $\left({ }^{\mathbf{}} \mathbf{C}\right)$ \\
\hline \hline$(-1)$ & 20 & 810 & 0.4 & 520 \\
\hline$(+1)$ & 60 & 2240 & 0.8 & 580 \\
\hline$(0)$ & 40 & 1525 & 0.6 & 550 \\
\hline
\end{tabular}


Table 2. Box-Behnken Design, Containing the Coded and Decoded Levels of the Factors and the Responses. Some Relevant Data

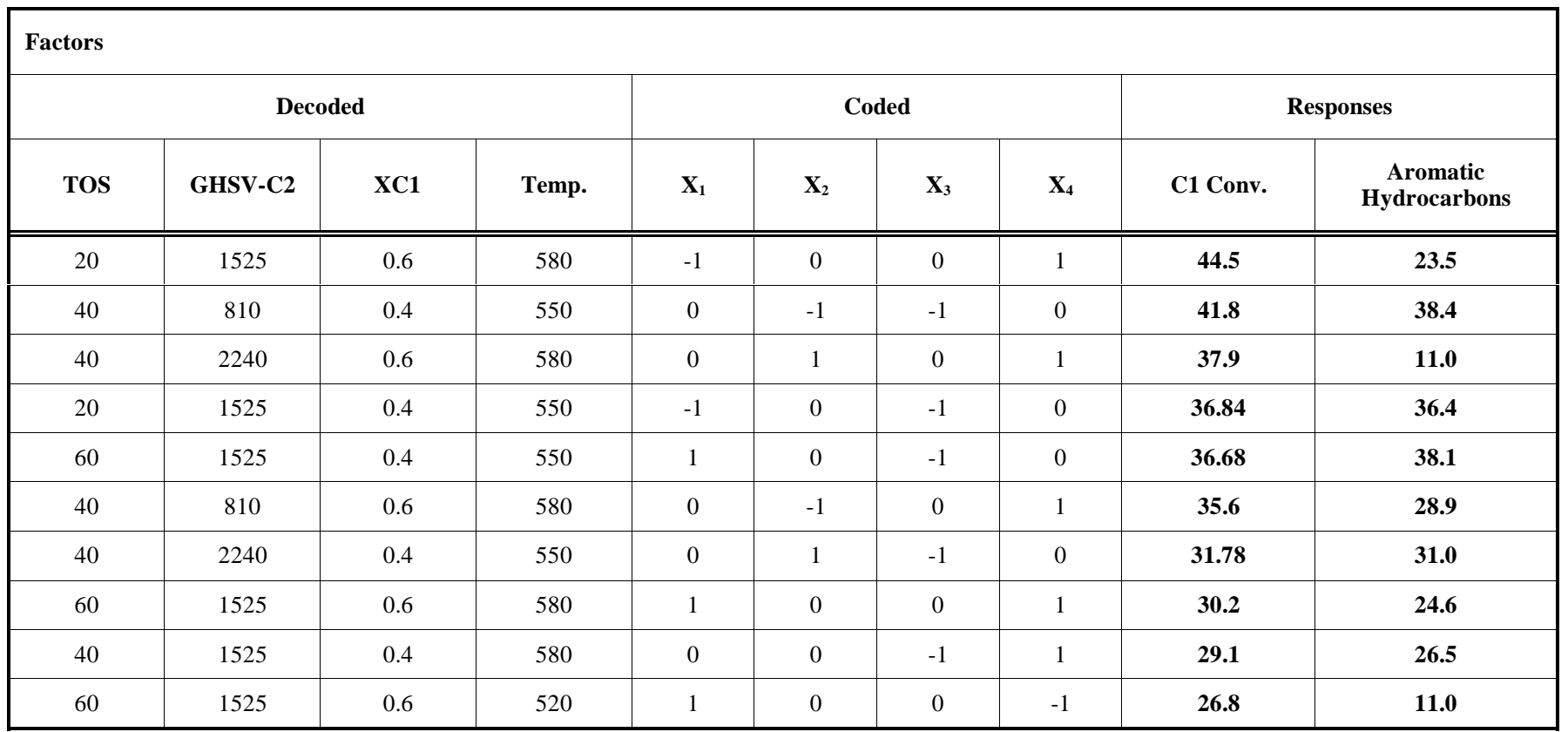

Table 3. Analysis of Variance to C1 Conversion (ANOVA)

\begin{tabular}{|c|c|c|c|c|c|}
\hline Source of Variation & Sumo of Squares & Df & Mean Squre & F-Ratio & P-Value \\
\hline $\mathrm{X}_{1}:(\mathrm{TOS})$ & 28.0296 & 1 & 28.0296 & 0.58 & 0.4570 \\
\hline $\mathrm{X}_{2}:(\mathrm{GHSV}-\mathrm{C} 2)$ & 76.2558 & 1 & 76.2552 & 1.58 & 0.2267 \\
\hline $\mathrm{X}_{3}:(\mathrm{XC} 1)$ & 1883.76 & 1 & 1883.76 & 39.06 & 0.0000 \\
\hline $\mathrm{X}_{4}$ : (Temp.) & 945.188 & 1 & 945.188 & 19.60 & 0.0004 \\
\hline $\mathrm{X}_{1} \mathrm{X}_{2}$ & 18.8356 & 1 & 18.8356 & 0.39 & 0.5408 \\
\hline $\mathrm{X}_{1} \mathrm{X}_{3}$ & 0.0001 & 1 & 0.0001 & 0.00 & 0.9989 \\
\hline $\mathrm{X}_{1} \mathrm{X}_{4}$ & 359.103 & 1 & 359.103 & 7.45 & 0.0149 \\
\hline $\mathrm{X}_{2} \mathrm{X}_{3}$ & 0.0006 & 1 & 0.0006 & 0.00 & 0.9972 \\
\hline $\mathrm{X}_{2} \mathrm{X}_{4}$ & 2.7225 & 1 & 2.7225 & 0.06 & 0.8152 \\
\hline $\mathrm{X}_{3} \mathrm{X}_{4}$ & 9.3025 & 1 & 9.3025 & 0.19 & 0.6664 \\
\hline Total error & 771.729 & 16 & 48.233 & & \\
\hline Total (exp.) & 4094.93 & 26 & & & \\
\hline
\end{tabular}

The results obtained by the ANOVA test show, in this case, that three effects are significantly different from zero at the $95.0 \%$ confidence level (these p-values were highlighted as bold values). These factors are XC1, temperature and the TOS-temperature interactions. The R-squared statistic [6] indicates that the model explains $81.15 \%$ of the variability in $\mathrm{C} 1$ conversion. In this case, this value indicates that the model explains the $81 \%$ of the total variations. The adjusted $R$-squared statistic, which is more suitable for comparing models with different numbers of independent variables, is $69.37 \%$.

According to the data showed in Table 4, the following aspect can be underlined: the parameters that produce higher effect are $X_{3}(\mathrm{XC} 1=-25), X_{4}$ (temperature $\left.=18\right)$ and the $X_{1}-$
$X_{4}$ interactions (TOS-temperature $=-19$ ). The positive sign in the effect of the temperature means that the change from the lower to the higher level of the factor implies an increase in the response in 19 units. The negative sign in the effects means that the change from the lower to the higher level of the factor implies a decreasing in the response.

The model equation for the response surfaces fitted to the experimental data points, in coded unit, considering the significant factors is as follows:

C1 Conversion $=21.6404-12.5292 * \mathrm{X}_{3}+8.875 * \mathrm{X}_{4}-$ $9.475 * \mathrm{X}_{1} * \mathrm{X}_{4}$

The contours of estimated response surface products of the design are shown in Fig. (1). 
Table 4. Estimated Effects for the C1 Conversion

\begin{tabular}{|c|c|}
\hline Factors & Effects \\
\hline \hline $\mathrm{X}_{1}:(\mathrm{TOS})$ & 3.06 \\
\hline $\mathrm{X}_{2}:($ GHSV-C2) & -5.04 \\
\hline $\mathrm{X}_{3}:(\mathrm{XC} 1)$ & $\mathbf{- 2 5 . 0 6}$ \\
\hline $\mathrm{X}_{4}:($ Temp. & $\mathbf{1 7 . 7 5}$ \\
\hline $\mathrm{X}_{1} \mathrm{X}_{2}$ & -4.34 \\
\hline $\mathrm{X}_{1} \mathrm{X}_{3}$ & -0.01 \\
\hline $\mathrm{X}_{1} \mathrm{X}_{4}$ & $\mathbf{- 1 8 . 9 5}$ \\
\hline $\mathrm{X}_{2} \mathrm{X}_{3}$ & -0.025 \\
\hline $\mathrm{X}_{2} \mathrm{X}_{4}$ & 1.7 \\
\hline $\mathrm{X}_{3} \mathrm{X}_{4}$ & -3.05 \\
\hline
\end{tabular}

In Table 5, the combinations of levels of factors that maximize the Conversion of $\mathrm{C} 1$ over the analyzed region are shown.

\subsection{RESPONSE: AROMATIC HYDROCARBONS YIELDS}

The results obtained by the ANOVA test are shown in Table 6 .

The results obtained by the ANOVA test show, in this case, that three effects are significantly different from zero at the $95.0 \%$ confidence level, see Table 6 . These factors are GHSV-C2, XC1 and Temperature. The $R$-squared statistic [6] indicates that the model explains $72.50 \%$ of the variability Aromatic Hydrocarbons yield. In this case, this value indicates that the model explains the $72 \%$ of the total variations. The adjusted $R$-squared statistic is $55.32 \%$.

According to the data showed in Table 7, the parameters that produce higher effect are $X 3$ (XC1 =-24), $\mathrm{X}_{2}$ (GHVS$\mathrm{C} 2=-11)$ and $\mathrm{X}_{4}($ Temperature $=9)$.

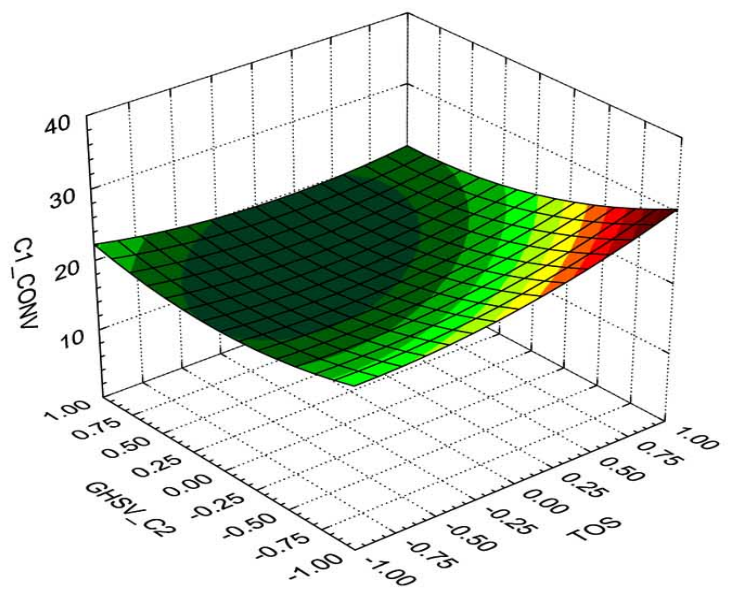

(a)

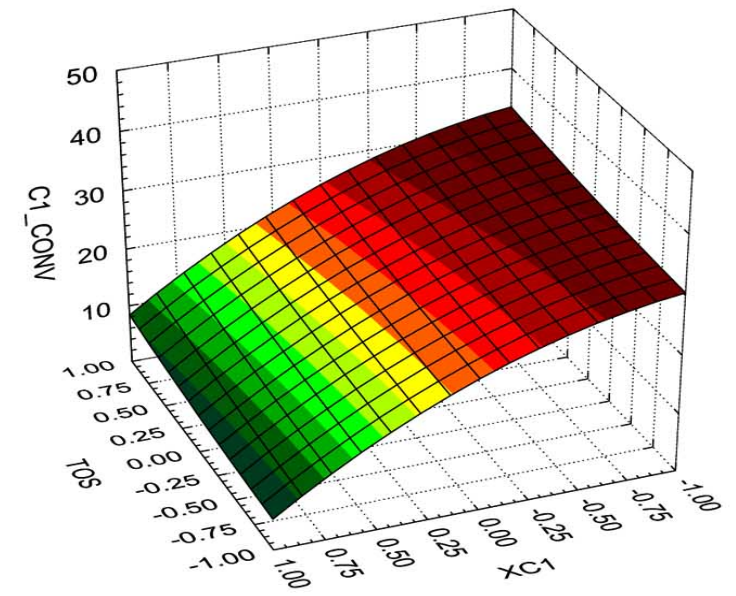

(b) 


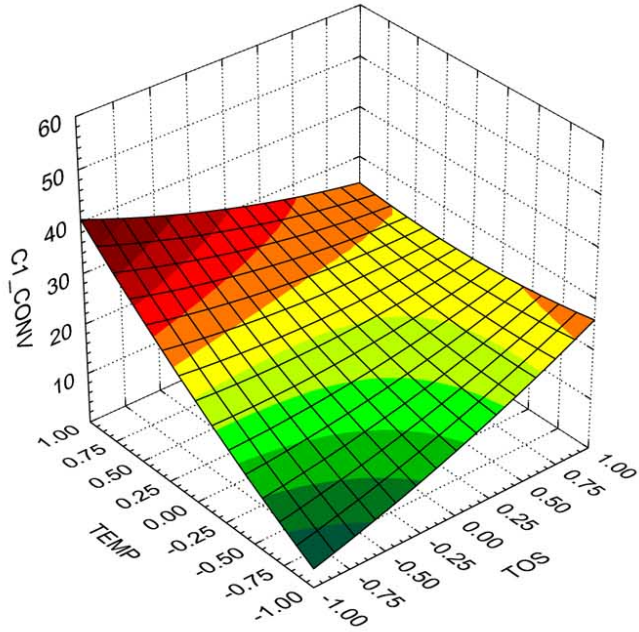

Fig. (1). contd....

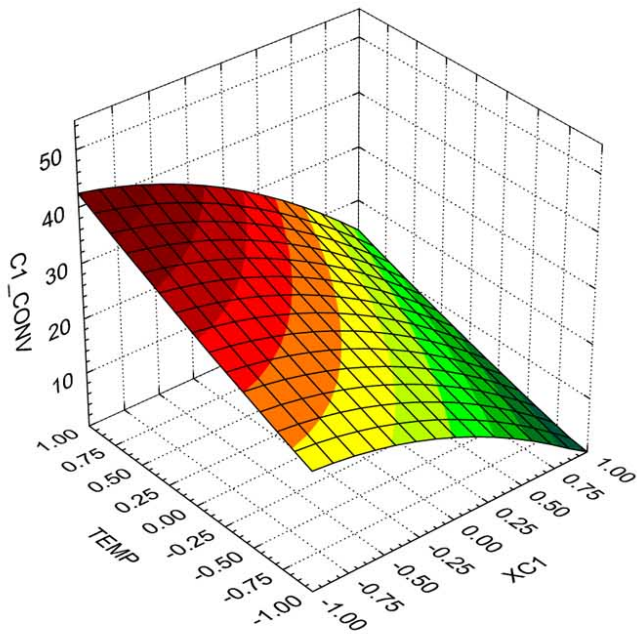

(c)

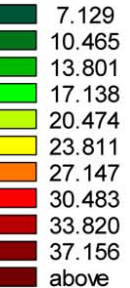

(d)

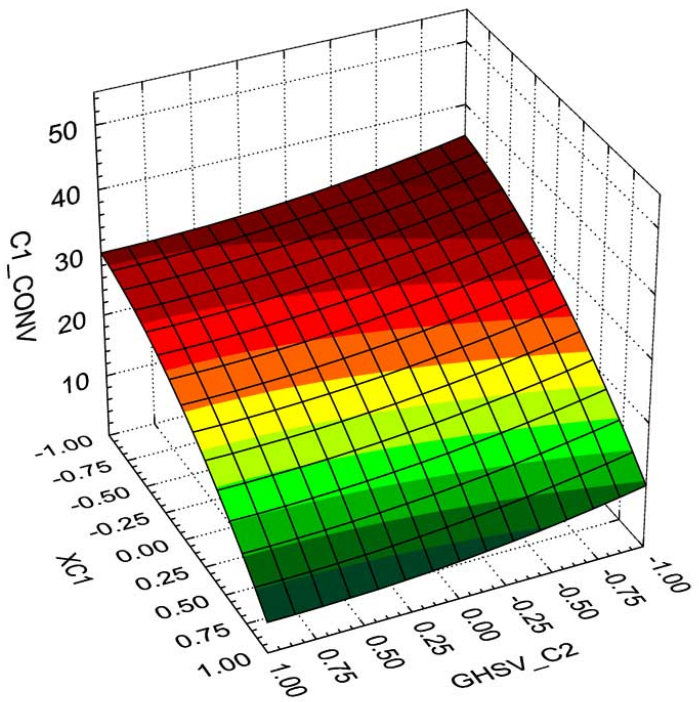

(e)

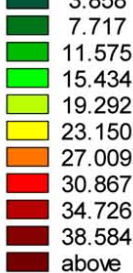


Fig. (1). contd....

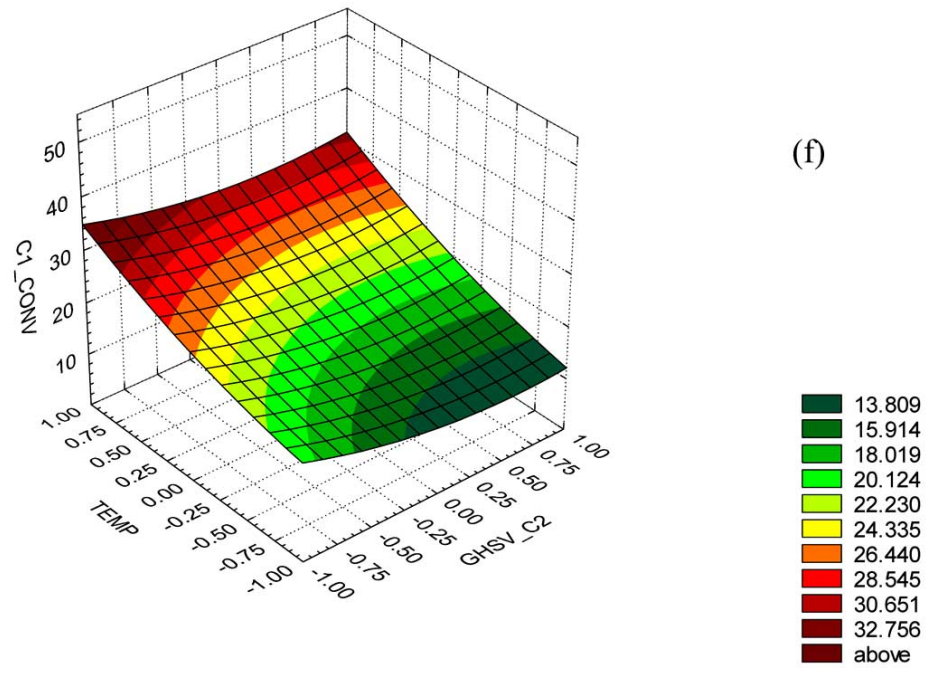

Fig. (1). Response surface fitted for the design. C1 conversion as a function of: (a) GHVS_C2 and TOS; (b) TOS and XC1; (c) Temperature and TOS; (d) Temperature and XC1; (e) XC1 and GHVS_C2; (f) Temperature and GHVS_C2.

Table 5. C1 Conversion Maximization

\begin{tabular}{|l|c|c|c|}
\hline \multicolumn{4}{|c|}{ Optimal Value $\mathbf{5 1 . 3 8 2 6}$} \\
\hline Factors & Inferior & Greater & Optimal \\
\hline \hline $\mathrm{X}_{1}:(\mathrm{TOS})$ & -1 & 1 & -1.0 \\
\hline $\mathrm{X}_{2}:(\mathrm{GHSV}-\mathrm{C} 2)$ & -1 & 1 & -0.8102 \\
\hline $\mathrm{X}_{3}:(\mathrm{XC} 1)$ & -1 & 1 & -0.9477 \\
\hline $\mathrm{X}_{4}:(\mathrm{Temp})$ & -1 & 1 & 1.0 \\
\hline
\end{tabular}

The model equation for the response surfaces fitted to the experimental data points, for the significant factors, is as follows:

Aromatic Hydroc. yields $=19.2533-5.415 * \mathrm{X}_{2}-11.765$

$* \mathrm{X}_{3}-4.565 * \mathrm{X}_{4}$

The contours of estimated response surface products of the design are shown in Fig (2).

Table 6. Analysis of Variance to Aromatic Hydrocarbons Yield
In Table 8, we show the combinations of levels of factors that maximize the Aromatic Hydrocarbons yields over the analyzed region.

Table 7. Estimated Effects for the Aromatic Hydrocarbons Yields

\begin{tabular}{|c|c|}
\hline Factors & Effects \\
\hline \hline $\mathrm{X}_{1}:(\mathrm{TOS})$ & 1.59 \\
\hline $\mathrm{X}_{2}:(\mathrm{GHSV}-\mathrm{C} 2)$ & -10.83 \\
\hline $\mathrm{X}_{3}:(\mathrm{XC} 1)$ & -23.53 \\
\hline $\mathrm{X}_{4}:(\mathrm{Temp})$. & 9.13 \\
\hline $\mathrm{X}_{1} \mathrm{X}_{2}$ & -0.2 \\
\hline $\mathrm{X}_{1} \mathrm{X}_{3}$ & -1.6 \\
\hline $\mathrm{X}_{1} \mathrm{X}_{4}$ & -4.39 \\
\hline $\mathrm{X}_{2} \mathrm{X}_{3}$ & -3.39 \\
\hline $\mathrm{X}_{2} \mathrm{X}_{4}$ & -11.2 \\
\hline $\mathrm{X}_{3} \mathrm{X}_{4}$ & -5.3 \\
\hline
\end{tabular}

\begin{tabular}{|c|c|c|c|c|c|}
\hline Source of Variation & Sum of Squares & Df & Mean Square & F-Ratio & P-Value \\
\hline $\mathrm{X}_{1}:(\mathrm{TOS})$ & 7.64803 & 1 & 7.64803 & 0.13 & 0.7218 \\
\hline $\mathrm{X}_{3}:(\mathrm{XC} 1)$ & 1660.98 & 1 & 1660.98 & 28.52 & 0.0001 \\
\hline $\mathrm{X}_{4}$ : (Temp.) & 250.071 & 1 & 250.071 & 4.29 & 0.0548 \\
\hline $\mathrm{X}_{1} \mathrm{X}_{4}$ & 19.2721 & 1 & 19.2721 & 0.33 & 0.5731 \\
\hline $\mathrm{X}_{2} \mathrm{X}_{3}$ & 11.4921 & 1 & 11.4921 & 0.20 & 0.6629 \\
\hline $\mathrm{X}_{2} \mathrm{X}_{4}$ & 125.44 & 1 & 125.44 & 2.15 & 0.1616 \\
\hline $\mathrm{X}_{3} \mathrm{X}_{4}$ & 28.09 & 1 & 28.09 & 0.48 & 0.4974 \\
\hline
\end{tabular}




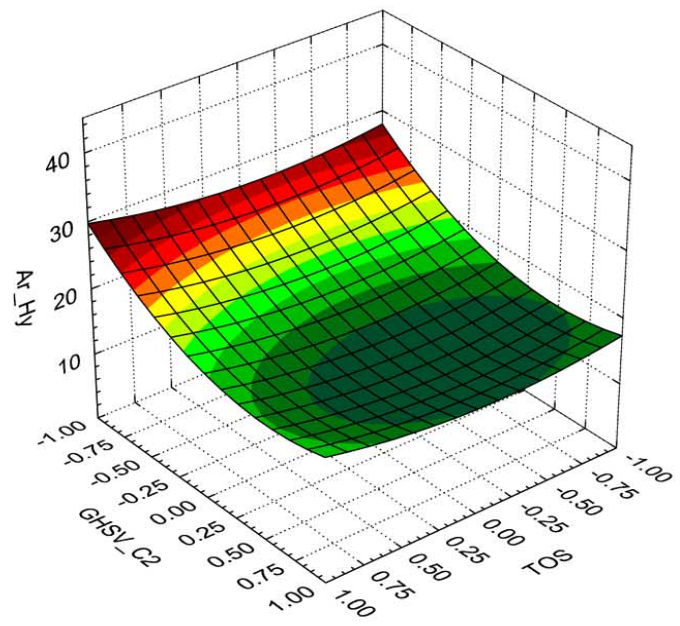

(a)

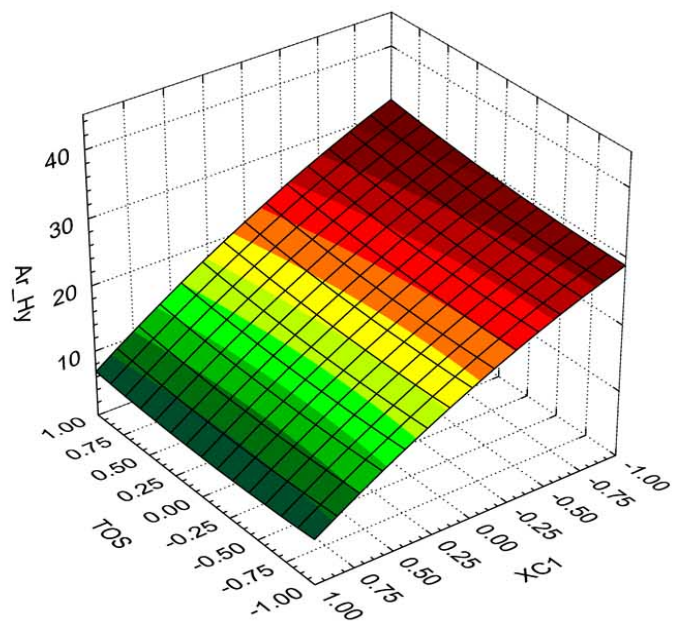

(b)

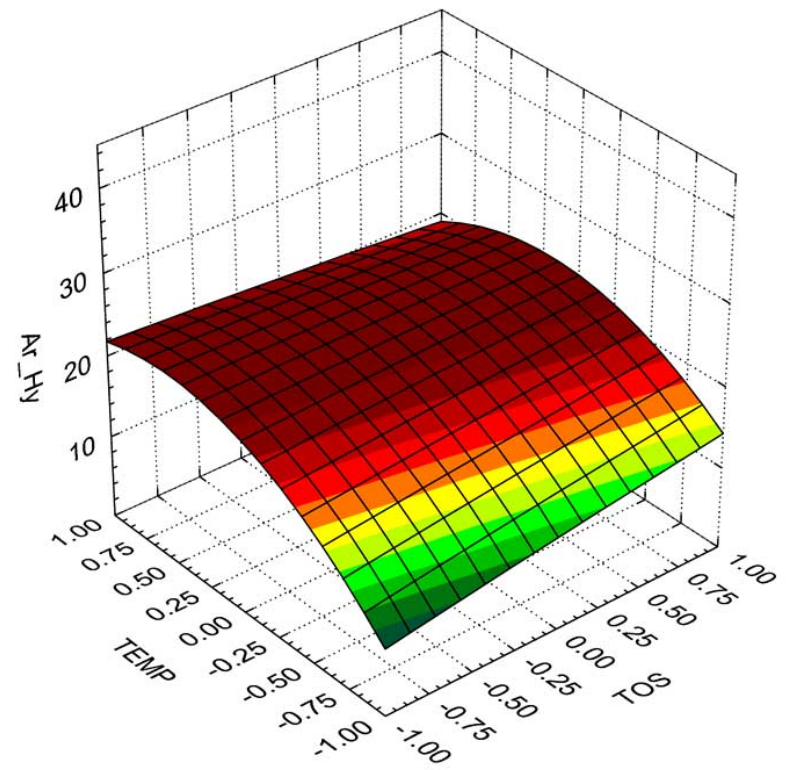

(c)

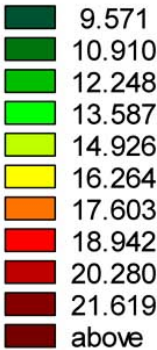


Fig. (2). contd....

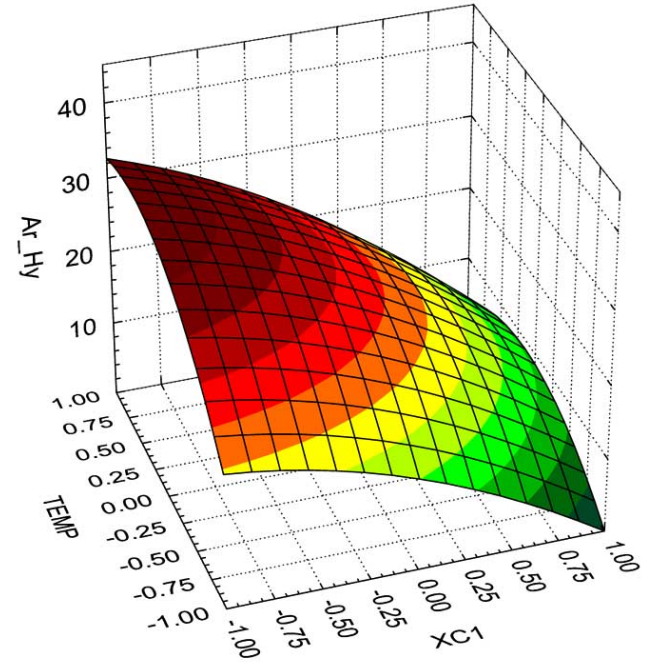

(d)

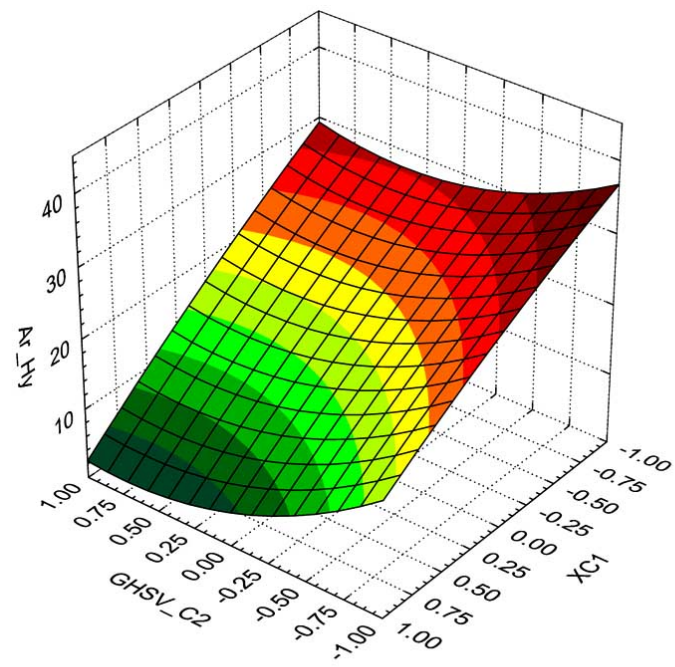

(e)
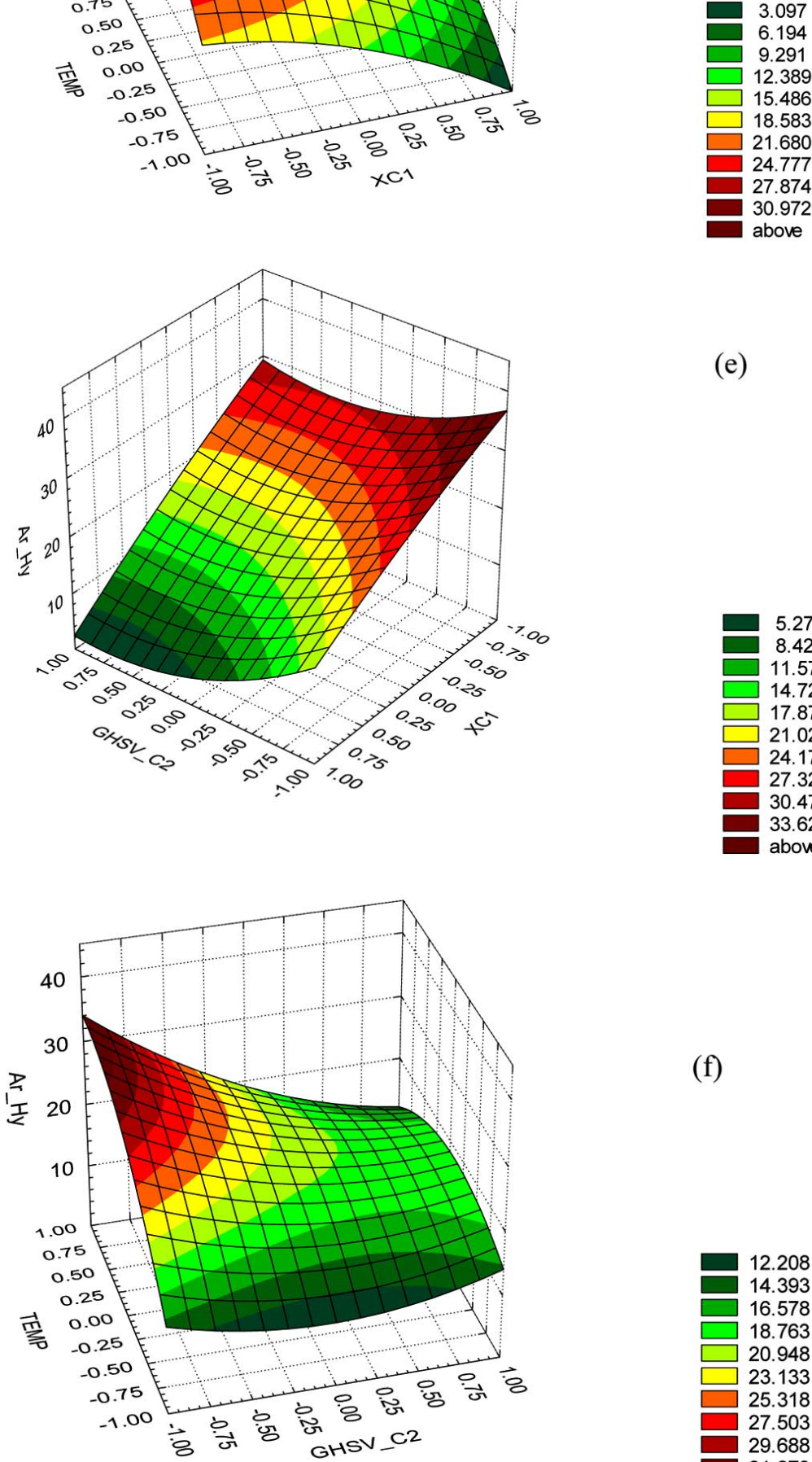

(f)

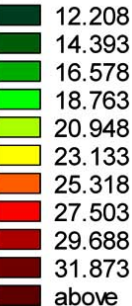

Fig. (2). Response surface fitted for the design. Aromatic Hydrocarbons yields as a function of: (a) GHVS_C2 and TOS; (b) TOS and XC1; (c) Temperature and TOS; (d) Temperature and XC1; (e) XC1 and GHVS_C2; (f) Temperature and GHVS_C2. 
Table 8. Aromatic Hydrocarbons Yields Maximization

\begin{tabular}{|l|c|c|c|}
\hline \multicolumn{4}{|c|}{ Optimal Value $=\mathbf{4 7 . 1 4 4 3}$} \\
\hline Factor & Inferior & Greater & Optimal \\
\hline \hline $\mathrm{X}_{1}:(\mathrm{TOS})$ & -1 & 1 & 0.3856 \\
\hline $\mathrm{X}_{2}:(\mathrm{GHSV}-\mathrm{C} 2)$ & -1 & 1 & -1.0 \\
\hline $\mathrm{X}_{3}:(\mathrm{XC} 1)$ & -1 & 1 & -0.9833 \\
\hline $\mathrm{X}_{4}:(\mathrm{Temp})$. & -1 & 1 & 1.0 \\
\hline
\end{tabular}

\subsection{Optimization}

Considering the equations (4) and (5), the responses surfaces obtained and the optimal values proposed by the design; and in order to find an optimal area of operation to increase the conversion of $\mathrm{C} 1$ and the Aromatic Hydrocarbons yields, six new experiments was carry out. These runs are shown in Table 9.

The statistic methodology applied in this work allows us suggesting the better operation conditions for this reaction to optimize the two responses. We propose the following as the optimal values for the variables:

$\mathrm{X}_{1}=\mathrm{TOS}: 20-40 \mathrm{~min}$

$\mathrm{X}_{2}=\mathrm{GHVS}-\mathrm{C} 2: 810-1200 \mathrm{ml} / \mathrm{g} \mathrm{h}$

$\mathrm{X}_{3}=\mathrm{XC1}: 0.2-0.4$

$\mathrm{X}_{4}=$ Reaction Temperature: $550-580{ }^{\circ} \mathrm{C}$

In order to corroborate the statistic result, we carried out several reactions and the experimental data are shown in Table 10.

The results showed in Table $\mathbf{1 0}$ allow us to obtain the optimal values of the reaction conditions, based on statistic analyses. With these data, we reach a higher $\mathrm{C} 1$ conversion $(50 \mathrm{~mol} \% \mathrm{C})$ and higher Aromatic yields (47 mol\% C). It is interesting to mark that we arrive to these conclusions considering the influence of the separate variables and their main interactions. The statistic model applied in this work, allowed us to interpret the overall process, considering the multivariate parameters. Applying the statistic methodology, the best operation conditions are that we obtained in Exp. 1. High C1 conversion (48.6 mol\% C) and Aromatic Hydrocarbons Yields (47.2 mol\%) were achieved working at these conditions, advancing to the results recently reported by us, where only one objective function ( $\mathrm{C} 1$ conversion) was optimized [4].

\section{DISCUSSION AND CONCLUSIONS}

A design of experiment was carried out in order to optimize the $\mathrm{C} 1$ conversion to aromatic hydrocarbons. The statistic model applied in this work allowed us to optimized two responses simultaneously. Applying the statistic methodology, the best operation conditions can be found. The highest $\mathrm{C} 1$ conversion $(\mathrm{mol} \% \mathrm{C})$ and the higher Aromatic yields were achieved working at these conditions. In the same way, the statistic methodology indicates that the following factors: $\mathrm{XC1}$, the reaction temperature and the TOS-temperature interaction, have the higher effects to $\mathrm{C} 1$ conversion; and the factors: GHVS_C2, XC1 and reaction temperature have the higher effects to Aromatic Hydrocarbons yields.

According to our previous results of $\mathrm{C} 1$ activation with C2 [2, 21], the reaction mechanism seems to be a Rideal type. Ethane is adsorbed onto the catalyst surface generating active ad-species, which are impacted for $\mathrm{C} 1$ from gas phase. As the extend of the reaction modeled by a Rideal type take place with one ad-species and other in gas phase, the reaction ride increases with the partial pressure of the gas phase species and the number of the chemisorbed ad-species. We suggest that, this is the reason because the $\mathrm{XC} 1$ between 0.2 - 0.4 produces sufficient quantities of $\mathrm{C} 2$ ad-species and optimum partial pressure of $\mathrm{C} 1$ for the reaction. Remember that we work at a total pressure equal at $1 \mathrm{~atm}$, as the $\mathrm{XC} 1$ increases to 0.8 it influences negatively tuned with lower $\mathrm{C} 2$ ad-species. If the reaction temperature increases to $580{ }^{\circ} \mathrm{C}$, $\mathrm{C} 1$ conversion increases but at higher reaction temperature such as $700{ }^{\circ} \mathrm{C}, \mathrm{C} 2$ is transformed alone in gas phase. When the time on stream increases over the levels of the factors selected by us (i.e. $100 \mathrm{~min}$ ), the catalyst begins to deactivate slowly, producing the diminution of $\mathrm{C} 1$ and $\mathrm{C} 2$ conversion. The $\mathrm{Zn}$-species incorporated into catalyst are active because its lower energy of its LUMO (lower unoccupied molecular orbital, acting as new and strong Lewis acid sites), allowing the chemisorption of active $\mathrm{C} 2$ ad-species, by the direct $\mathrm{ab}$ -

Table 9. C1 Conversion and Aromatic Hydrocarbons Yields, in the Optimal Reaction Conditions

\begin{tabular}{|c|c|c|c|c|c|c|c|c|c|}
\hline \multicolumn{10}{|c|}{ Factors } \\
\hline \multicolumn{4}{|c|}{ Decoded } & \multicolumn{4}{|c|}{ Coded } & \multicolumn{2}{|c|}{ Responses } \\
\hline TOS & GHSV-C2 & XC1 & Temp & $\mathbf{X}_{1}$ & $\mathbf{X}_{2}$ & $\mathbf{X}_{3}$ & $\mathbf{X}_{4}$ & C1 Conv & $\begin{array}{c}\text { Aromatic } \\
\text { Hydrocarbons }\end{array}$ \\
\hline 20 & 810 & 0.4 & 580 & -1 & -1 & -1 & 1 & 44.5 & 29.9 \\
\hline 40 & 810 & 0.4 & 580 & 0 & -1 & -1 & 1 & 38 & 29.4 \\
\hline 60 & 810 & 0.4 & 580 & 1 & -1 & -1 & 1 & 30.2 & 27.6 \\
\hline 20 & 1525 & 0.4 & 580 & -1 & 0 & -1 & 1 & 46.9 & 20.9 \\
\hline 20 & 2240 & 0.4 & 580 & -1 & 1 & -1 & 1 & 45.5 & 13.5 \\
\hline 40 & 1525 & 0.6 & 550 & 0 & 0 & 0 & 0 & 21.1 & 20.5 \\
\hline
\end{tabular}


Table 10. C1 Conversion to Aromatic Hydrocarbons, in the Optimal Reactor Conditions

\begin{tabular}{|c|c|c|c|c|c|c|}
\hline Exp & TOS (min) & GHVS_C2 (ml/g.h) & XC1 & Temp. $\left({ }^{\circ} \mathbf{C}\right)$ & C1 Conv. $(\mathbf{m o l} \% \mathbf{C})$ & Aromatic Hydrocarbons (mol\%C) \\
\hline \hline 1 & 20 & 810 & 0.2 & 550 & 48.6 & 47.2 \\
\hline 2 & 40 & 1200 & 0.2 & 580 & 50.5 & 44.1 \\
\hline 3 & 40 & 810 & 0.4 & 550 & 50.0 & 37.0 \\
\hline 4 & 20 & 810 & 0.4 & 580 & 50.4 & 33.0 \\
\hline
\end{tabular}

straction of a hydride producing a carbenium-like surface species through electron-donor-acceptor adducts (EDA) formation. Then, these species react in order to produce intermediates as $\mathrm{C}_{3}$ and $\mathrm{C}_{4}$ and more reactive olefins $\left(\mathrm{C}_{2=}, \mathrm{C}_{4=}\right)$ and latter isoparaffin $\left(\mathrm{i}-\mathrm{C}_{4}\right)$. The carbenium ad-species formed from them interact with $\mathrm{C}_{1}$ producing its transformation to naphthenic and aromatics. It is interesting to observe, that the presence of strong Lewis sites (SLS) on the catalyst prevents the hydrogenation of intermediate alkenes, which would be efficiently introduced into polymerization, cyclization, dehydrogenation and aromatization complex mechanism. The statistic model applied in this work is a powerful tool to interpret the overall process from the multivariate parameters.

\section{ACKNOWLEDGEMENTS}

O.A.A, and J.C Conicet Researcher. The authors are grateful to CONICET PIP 112-200801-00388 and MINCyT Cba. PIP 1210/07

\section{REFERENCES}

[1] Anunziata, O.A.; Eimer, G.A.; Pierella, L.B. Methane transf. into AH by activation with LPG over Zn-ZSM11 zeolite. Catal. Lett., 1999, 58, 235-239.

[2] Anunziata, O.A.; Eimer, G.A.; Pierella, L.B. Catalytic conv. of NG with added C2 and LPG over Zn-ZSM-11. Appl. Catal. A: Gen., 2000, 190, 169-176.

[3] Pierella, L.B.; Eimer, G.A.; Anunziata, O.A. C1 Trans into AH over Zn-ZSM-11 Zeolite. Stud. Surf. Sci. Catal. Nat. Gas Convers., 1998, 119, 235-240.

[4] Anunziata, O.A.; Cussa, J. Apply of Response Surface Design to the optimization of methane activation with ethane over $\mathrm{Zn}-\mathrm{H}$ ZSM-11 zeolite. Chem. Eng. J., 2008, 138, 510-516.

[5] Fisher, R.A. The Design of Experiments. $2^{\text {nd }}$ ed.; Oliver and Boyd. Edinburg, 1937.

[6] Box, G.E.P.; Wilson, K.B. On the experimental attainment of optimum conditions. J. R. Stat. Soc. Ser. B, 1951, 13, 1-45.
[7] Box, K.B.; Behnken, D.W. Some new three level designs for the study of quantitative variables. Technometrics $2 \mathbf{1 9 6 0}, 455$ 475.

[8] Box, G.E.P.; Hunter, W.G.; Hunter, J.S. Statistics for Experimenters: An Introduction to Design, Data Analysis, and Model Building. John Wiley and Sons, New York, 1978.

[9] Cox, D.R. Planning of Experiments. John Wiley \& Sons, Inc., New York, 1958.

[10] Kempthorne, O. The Design and Analysis of Experiments. Robert E. Krieger Publishing Company. Malabar (FL), 1979.

[11] Cochran, W.G.; Cox, G.M. Experimental Design. John Wiley \& Sons, Inc., New York, 1957.

[12] Kuehl, R.O. Design of Experiments. $2^{\text {nd }}$ ed., Duxbury- Thomson Learning, Pacific Grove, 2000

[13] Montgomery, D.C. Design and Analysis of Experiments. John Wiley \& Sons, Inc., New York, 1991.

[14] Ferreira-Dias, S.; Correia, A.C.; Baptista, F.O.; da Fonseca, M.M.R. Contribution of response surface design to the development of glycerolysis systems catalyzed by commercial immobilized lipases J. Mol. Catal. B: Enzyme, 2001, 11, 699-711.

[15] Øye, G.; Sj"oblom, J.; St"ocker, M. A multivariate analysis of the synthesis conditions of mesoporous materials. Microporous Mesoporous Mater, 2000, 34291-299.

[16] Guervenou, J.; Giamarchi, P.; Coulouarn, C.; Guerda, M.; le Lez, C. ; Oboyet, T. Experimental design methodology and data analysis technique applied to optimise an organic synthesis. Chemometr. Intell. Lab. Syst., 2002, 63, 81-89.

[17] Anunziata, O.A.; Beltramone, A.R.; Cussa, J. Stud. of Vit. K3 synt. over Ti-cont. mesoporous material. J. Appl. Catal. A: Gen., 2004, 270,77-85.

[18] Du, G.; Yang, Y.; Qiu, W.; Lim, S.; Pfefferle, L.; Haller, G.L. Statistical design and modeling of the process of methane partial oxidation using V-MCM-41 catalysts and the prediction of the formaldehyde production. Appl. Catal. A: Gen., 2006, 313, 113 .

[19] Sen, M.; Shan, H.S. Electro jet drilling using hybrid NNGA approach. Robot. Comput. Integr. Manufact., 2007, 2317.

[20] Domínguez Domínguez, J. Optimización simultánea para la mejora continua y reducción de costos en procesos. Ingeniería Cien., 2006, 4, 145.

[21] Anunziata, O.A.; Eimer, G.A.; Pierella, L.B. Ethane conversion into aromatic hydrocarbons over molybdenum-containing MEL zeolites. Appl. Catal. A: Gen., 1999, 182, 267.

This is an open access article licensed under the terms of the Creative Commons Attribution Non-Commercial License (http://creativecommons.org/licenses/ by-nc/3.0/) which permits unrestricted, non-commercial use, distribution and reproduction in any medium, provided the work is properly cited. 